\title{
Comparative sensitivity of a cultural test and the complement fixation test in the diagnosis of adenovirus ocular infection
}

\author{
J. A. GIBSON, ${ }^{1}$ S. DAROUGAR, ${ }^{1}$ D. A. MCSWIGGAN, ${ }^{2}$ AND U. THAKER ${ }^{1}$ \\ From the ${ }^{1}$ Virus Laboratory, Department of Clinical Ophthalmology, Institute of Ophthalmology, \\ Judd Street, London, and External Eye Diseases Clinic, Moorfields Eye Hospital, City Road, London \\ and the ${ }^{2}$ Public Health Laboratory and Department of Microbiology, Central Middlesex Hospital, \\ Acton Lane, Park Royal, London NW10
}

SUMMARY The sensitivity of human embryonic kidney (HEK) cell culture and the complement fixation test (CFT) in the diagnosis of adenovirus ocular infection has been compared. The optimum time for collection of specimens to obtain the best results by each test has been examined. Sixty-one $(53 \%)$ of 116 patients with moderate to severe follicular conjunctivitis, clinically indicative of adenovirus infection, had serological evidence of infection or had the virus isolated from ocular swabs. Virus was isolated from 53 patients $(45 \%)$ and significant antibody rises were found in 33 $(27 \%)$. When each test was carried out under optimum conditions, virus was isolated from $82 \%$ of cases and serological evidence of infection found in $72 \%$. Serological responses as detected by the CFT appeared to be inferior in infections caused by adenovirus type 7 to those encountered in infections due to adenovirus types 3 and 8 .

The ocular morbidity associated with adenovirus infections varies considerably. These eye infections constitute a major economic problem owing to the loss of a considerable number of working days each year. Sporadic cases of acute follicular conjunctivitis and keratoconjunctivitis caused by various serotypes of adenovirus are common entities. Adenovirus serotypes $3,4,7,8$, and 19 particularly are responsible for outbreaks of the disease in hospitals, factories, and schools (Editorial, 1977).

Several laboratory tests are available for the diagnosis of adenovirus ocular infection. Cell cultures for virus isolation and the complement fixation test (CFT) for detection of antibody to adenovirus group antigen are routine laboratory procedures which are extensively used for the diagnosis of ocular infection.

In this paper we compare the sensitivity of a primary human embryonic kidney (HEK) cell culture system with the complement fixation test for the diagnosis of adenovirus infection of the eye. The optimum time for collection of specimens

Correspondence to Dr S. Darougar, Institute of Ophthalmology, Judd Street, London WC1H 9QS. to obtain the highest positivity rate by each test is discussed.

\section{Materials and methods}

SELECTION OF PATIENTS

Patients attending the clinic with moderate to severe follicular conjunctivitis or keratoconjunctivitis clinically suggestive of an adenovirus infection were included in this study.

\section{CULTURAL TEST}

Swabbings collected from different areas of the conjunctiva (Darougar and Jones, 1971) were placed in plastic capsules containing 2SP transport medium (Gordon et al., 1969) with additional fetal bovine serum, and stored at $-70^{\circ} \mathrm{C}$ until required.

Each specimen was inoculated into 2 tubes of HEK cells and examined at regular intervals for the presence of cytopathic effect (CPE) for up to - 21 days (McSwiggan et al., 1975). The isolates were identified and serotyped by standard methods.

SEROLOGICAL TEST

Serum collected by venepuncture was tested by a complement fixation test (Bradstreet and Taylor, 
1962) for detection of antibody against adenovirus group antigen.

STATISTICS

Results were submitted to statistical tests of significance by the chi-square test.

\section{Results}

VIRUS ISOLATION

A total of 125 specimens were collected from 116 patients. Of these, $53(45 \%)$ yielded adenoviruses; the various serotypes isolated are shown in Table 1. The isolation rates in relation to the time of collection of specimens after the onset of symptoms are shown in Fig. 1. Of the specimens collected during the first week of ocular infection $66 \%$ (41 out of 62 ) were positive. The isolation rate dropped to $25 \%$ (7 out of 28) for the specimens taken during the second week of infection and fell further to $12 \%$ ( 2 out of 17) in specimens collected during the third and fourth week of infection. Of 18 specimens collected during the second month of infection 3 were positive, 2 yielded adenovirus type 3 (isolated 52 and 58 days after onset), and 1 yielded adenovirus type 8 , isolated 50 days after onset.

\section{COMPLEMENT FIXATION TEST}

Where 2 or more convalescent sera were available from 1 patient, each was paired with the acute serum separately. This gave a total of 210 paired sera from the 116 patients included in this study. The complement fixation test on these paired sera showed a 4-fold or higher rise in titre of group antibody against adenovirus in $33(28 \%)$ of cases and less than 4-fold or no rise in $34(29 \%)$. In the remaining cases antibody to adenovirus was not detected.

Table 1 Distribution of adenovirus serotypes among 53 isolates

\begin{tabular}{ll}
\hline Serotype & Number $(\%)$ of isolates \\
\hline 1 & $1(2)$ \\
3 & $16(30)$ \\
4 & $2(4)$ \\
5 & $3(6)$ \\
7 & $12(23)$ \\
8 & $12(23)$ \\
19 & $4(7)$ \\
$15 / 29$ & $1(2)$ \\
Untyped & $2(4)$ \\
\hline
\end{tabular}

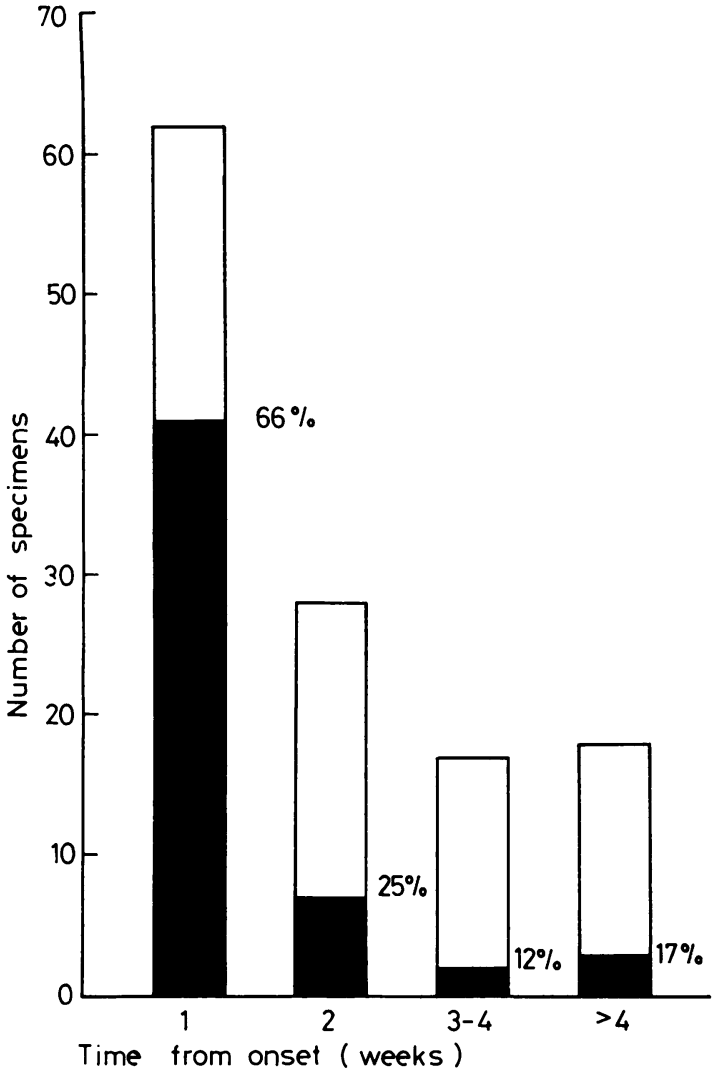

Fig. 1 Adenovirus isolation rate in relation to the time of collection of specimens after the onset of infection

The result of antibody tests in relation to the time of collection of acute and convalesent sera from the onset of ocular infection is shown in Fig. 2. When the acute serum was obtained within 1 week and the convalescent serum 3-5 weeks after onset of disease, 16 of the $33(48 \%)$ sets of paired sera showed a significant (4-fold or higher) rise in antibody titre. This figure dropped to 5 out of 27 $(19 \%)$ when the convalescent serum was not collected until after 5 weeks. When the acute serum was collected during the second week and the convalescent serum within 3-5 weeks of infection, a significant rise in antibody was observed in only 3 out of $20(15 \%)$ sets; this dropped to 4 out of 62 $(6 \%)$ if the convalescent serum was not obtained until after 5 weeks (Fig. 2).

The serological responses in relation to serotypes of adenovirus were studied in cases where the acute serum was taken during the first week of infection. The results. (Table 2) suggest that adenovirus types 3 and $\mathbf{8}$ tend to produce a higher antibody response 


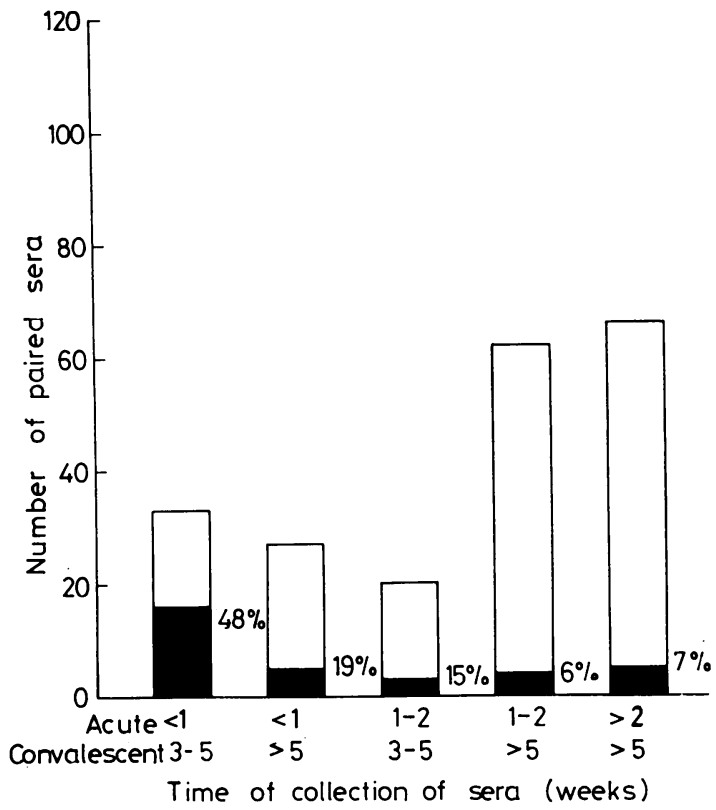

Fig. 2 Complement fixation positivity rate in relation to the time of collection of sera after the onset of infection

Table 2 Serological response in patients infected with different adenovirus serotypes

\begin{tabular}{lll}
\hline Serotype & Number of cases* & Number CFT + ve \\
\hline 3 & 13 & 8 \\
4 & 1 & 1 \\
5 & 2 & 2 \\
7 & 8 & 2 \\
8 & 8 & 5 \\
19 & 3 & 2 \\
$15 / 29$ & 1 & 0 \\
\hline
\end{tabular}

*Number of cases in which the first serum was taken at $\leqslant 7$ days after the onset of symptoms.

tCases showing four-fold or greater rise in CF titre.

(as detected by CFT) than adenovirus type 7 . The number of patients infected with various serotypes of adenovirus was not large enough to allow a valid conclusion.

COMPARATIVE SENSITIVITY OF CULTURAL AND COMPLEMENT FIXATION TESTS

Sixty-one of the 116 patients in this study had evidence of infection with adenoviruses as shown by virus isolation or by antibody tests or both. Cultural test was positive in $53(45 \%)$ and CFT in $33(27 \%)$. This difference between the 2 tests is statistically significant $(\mathrm{P}<0.05)$. Of the 53 patients from whom adenoviruses were cultured $25(47 \%)$ had serological evidence of infection. Conversely, of the 33 patients 'positive' by CFT, adenoviruses were isolated from $25(76 \%)$.

In patients in whom conjunctival swabbings for isolation of adenovirus were collected during the first week of infection and in those in whom the acute samples of serum were also collected during this period and the convalescent serum within 3-5 weeks of infection (the optimum set of circumstances for each group) the cultural test was positive in $82 \%(41 / 48)$ and the CFT was positive in $72 \%$ $(29 / 40)$. Thus, under optimum conditions the sensitivity of the 2 tests did not differ significantly.

\section{Discussion}

In this study adenovirus was isolated by the HEK cell culture system from $45 \%$ of patients with suggestive adenovirus ocular infection. This primary cell culture is shown to be as sensitive as HEp2 cells but is more sensitive than HeLa and W138 cell cultures for isolation of adenovirus (McSwiggan et al., 1975).

In the present study we found that the isolation rate of adenovirus is dependent on the time of collection of specimens from the onset of ocular infection. The isolation rate obtained in specimens collected during the first week of infection was 3-5 times higher than the rate obtained in specimens collected after the first week. This finding confirms previous reports (Mitsui et al., 1957, 1959; Ellison et al., 1969; Dawson et al., 1970) that early collection of specimens from patients with adenovirus infection is an important factor in obtaining satisfactory results from cultural tests.

In 3 patients with follicular conjunctivitis adenovirus serotypes 3 and 8 were isolated during the 8th and 9th weeks of infection. This tends to support a previous report (Darougar et al., 1977) that certain adenovirus serotypes are capable of causing chronic ocular infection.

In our group of patients the CFT was a less sensitive indicator of infection than the culture test ( $27 \%$ and $45 \%$ of cases respectively). As with the culture test, sensitivity of the serological tests depended on the time of collection of the acute and convalescent sera. The maximum index of infection $(72 \%)$ was obtained by CFT when the acute serum was collected during the first week of illness and the convalescent serum obtained not later than 5 weeks from the onset of disease. It has been shown, however, that when conjunctival swabbings for the 
cultural test and sera for CFT were collected at the optimum times no significant difference was observed between the sensitivity of these 2 tests for diagnosis of adenovirus infection.

The results of this study suggest that the serological responses detectable after adenovirus 7 infections are weaker than those following infection with adenovirus serotypes 3 and 8 . The numbers of infections with various serotypes were too small in this study to allow a conclusion to be drawn, but this is an aspect of the serology of adenovirus ophthalmic infections which will require further study.

This study was partially supported by a Locally Organised Clinical Research Grant, Moorfields Eye Hospital, for the study of adenovirus keratoconjunctivitis.

\section{References}

Bradstreet, C. M. P., and Taylor, C. E. D. (1962). Technique of complement fixation test applicable to the diagnosis of virus diseases. Monthly Bulletin of the Ministry of Health and the Public Health Laboratory Service, 21, 96-104.

Darougar, S., and Jones, B. R. (1971). Conjunctival swabbing for the isolation of TRIC agent (Chlamydia). British Journal of Ophthalmology, 55, 585-590.

Darougar, S., Quinlan, M. P., Gibson, J. A., Jones, B. R., and McSwiggan, D. A. (1977). Epidemic keratoconjunctivitis and chronic papillary conjunctivitis in London due to adenovirus type 19. British Journal of Ophthalmology, 61, 76-85.

Dawson, C. R., Hanna, L., Wood, T. R., and Despain, R. (1970). Adenovirus type 8 keratoconjunctivitis in the United States. American Journal of Ophthalmology, 69, 473-480.

Editorial (1977). Adenovirus keratoconjunctivitis. British Journal of Ophthalmology, 61, 73-75.

Ellison, E. D., Kaufman, H. E., and Little, J. M. (1969). Comparison of methods for the laboratory diagnosis of ocular adenovirus type 3 infection. Investigative Ophthalmology, 8, 484-487.

Gordon, F. B., Harper, I. A., Quan, A. L., Treharne, J. D., Dwyer, R. St. C., and Garland, J. A. (1969). Detection of Chlamydia (Bedsonia) in certain infection of man 1 . laboratory procedures: comparison of yolk sac and cell culture for detection and isolation. Journal of Infectious Diseases, 120, 451-462.

McSwiggan, D. A., Darougar, S., Rahman, A. F. M. S., and Gibson, J. A. (1975). Comparison of the sensitivity of human embryonic kidney cells, HeLa cells and W138 cells for the primary isolation of viruses from the eye. Journal of Clinical Pathology, 28, 410-413.

Mitsui, Y., Hanna, L., Hanabusa, J., Mindoa, R., Ogata, S., Kurihara, H., Okamura, R., and Miura, M. (1959). Association of adenovirus type 8 with epidemic keratoconjunctivitis. Archives of Ophthalmology, 61, 891-898.

Mitsui, Y., Hanabusa, J., Minoda, R., and Ogata, S. (1957). Effect of inoculating adenovirus (APC virus) type 8 into human volunteers. American Journal of Ophthalmology, 43, 84-90. 